К.В. Муравьев*

\title{
ТОЧНОСТЬ ПРЕДВАРИТЕЛЬНОЙ ЮРИДИЧЕСКОЙ ОЦЕНКИ СОДЕЯННОГО И ПРЕДЕЛЫ СУДЕБНОГО РАЗБИРАТЕЛЬСТВА В УСТАВЕ УГОЛОВНОГО СУДОПРОИЗВОДСТВА И СОВРЕМЕННОМ ПРАВЕ
}

Аннотация: Предметом исследования являются нормы отечественного уголовно-процессуального права, содержащие требования отражать юридическую оценку деяния при производстве по уголовному делу. Поддерживая позиции ученых-процессуалистов дореволючионного и новейшего времени о неразрывной связи материального и процессуального уголовного права, автор поставил цель провести сравнительный анализ положений Устава уголовного судопроизводства Российской империи и Уголовно-процессуального кодекса Российской Федерации по вопросу о возможности правильного применения материального уголовного закона в уголовном процессе лицами, ведущему производство по делу. В статье осуществляется сравнительный анализ положений Устава уголовного судопроизводства Российской империи и Уголовно-процессуального кодекса Российской Федерации. Автор обосновывает, что требование действующего закона о точной юридической оценке содеянного в актах досудебных стадий процесса является избыточным. Обращение к положениям Устава уголовного судопроизводства, разъяснениям Сената, нормам международного права, позиции Конституционного Суда РФ и взглядам процессуалистов приводит автора к выводу о необходимости совершенствования регулирования пределов судебного разбирательства в УПК РФ.

Ключевые слова: Устав уголовного судопроизводства, квалификация, уголовно-правовая оценка, пределы судебного разбирательства, применение уголовного закона, юридическая оценка, процессуальный акт, обвинительный акт, обвинение, суд.

DOI: 10.7256/1994-1471.2014.5.11334

B юридической литературе и дореволюционного, и новейшего времени преобладает точка зрения о неразрывной связи уголовного права и процесса. Так, С. И. Викторский определял уголовно-процессуальное право как совокупность норм, созданных для решения вопросов о применении норм материального уголовного права в каждом отдельном случае правонарушения ${ }^{1}$. Я.И. Баршев отмечал, что высшее и коренное начало уголовного судопроизводства должно состоять в правди-

Викторский С. И. Русский уголовный процесс. М., 1911. C. 2. вом осуществлении и приведении в действие уголовных законов ${ }^{2}$. И.Я. Фойницкий указывал, что уголовный процесс существенно необходим для применения уголовно-правовых норм ${ }^{3}$. По мнению А.Д. Прошлякова, материальное и процессуальное уголовное право (наряду с уголовно-исполнительным правом) образуют единый уголовно-правовой комплекс.

2 Баршев Я.И. Основания уголовного судопроизводства с применением к российскому уголовному судопроизводству. М., 2001. С. 41.

Фойницкий И.Я. Курс уголовного судопроизводства. Т. 1 СПб., 1996. С. 4.

(C) Муравьев Кирилл Владимирович

* Кандидат юридических наук, доцент кафедры уголовного процесса, Омская академия МВД России [murki@list.ru]

644092, Россия, г. Омск, пр. Комарова, д. 7.

Материалы международной научно-практической Конференции «Уголовное судопроизводство: история и современность», посвященной 150-летию Устава уголовного судопроизводства Российской империи. 
Данные отрасли неразрывно связаны между собой исторически и генетически, общими целями, задачами, принципами и т.д. ${ }^{4}$ А.П. Гуляев обращает внимание, что смысл всей уголовно-процессуальной деятельности заключается в претворении в жизнь уголовного закона, применение его норм является неотъемлемой и важнейшей частью этой деятельности. Он отмечает, что правильное применение уголовного закона является первоочередной задачей уголовного процесса 5 .

Тесная взаимосвязь составных частей уголовно-правового комплекса ежедневно проявляется в правоприменительной деятельности. Действующий Уголовно-процессуальный кодекс (далее - УПК РФ) на протяжении всего производства предусматривает большое число актов, в которых должностное лицо, ведущее дело, обязано давать уголовно-правовую оценку деянию, по поводу которого осуществляется процесс. В частности, в досудебном производстве такими решениями являются: постановление о возбуждении уголовного дела (ч. 2 ст. 146 УПК РФ), уведомление о подозрении в совершении преступления (ч. 2 ст. 223.1 УПК РФ), постановление о привлечении в качестве обвиняемого (ч. 2 ст. 171 УПК РФ), досудебное соглашение о сотрудничестве (ч. 2 ст. $317^{3}$ УПК РФ), обвинительные заключение, акт и постановление (ч. 1 ст. 220 , п. 5 ч. 1 ст. 225 , ч. 1 ст. $226^{7}$ УПК РФ) и др.

УПК РФ «призывает» лиц, ведущих производство по уголовному делу, не только к правильному, но и к точному применению уголовного закона на всех стадиях процесса, включая этапы досудебного производства. В указанных выше процессуальных актах он не допускает использование общей юридической оценки содеянного по родовому, видовому объекту (например, «преступление в сфере экономики», «преступление против собственности»), через признаки отдельной группы преступлений («хищение») или даже через указание на определенный состав («кража»). УПК РФ предъявляет требование, в соответствии с которым

\footnotetext{
4 Прошляков А.Д. Взаимосвязь материального и процессуального уголовного права. Екатеринбург, 1997. C. 22 .

Гуляев А. П. Цели, задачи и принципы как фундаментальные положения уголовно-процессуального права: по закону, теории и практике // Рос. следователь. 2012 № 16. С. 5-8. Справедливости ради отметим, что существуют и иные позиции по вопросу о соотношении отраслей уголовного и уголовно-процессуального права в том числе их ограниченной самостоятельности и даже независимости. Анализ точек зрения сделан в интересной работе Е.Г. Васильевой. См.: Её. Уголовный процесс: догматико-аксиологическое исследование: монография. М., 2013. С. 15-69.
}

в постановлениях следователя, дознавателя должны быть указаны конкретные пункт, часть и статья Уголовного кодекса.

Юридическая оценка деяния выступает в качестве результата уголовно-процессуальной деятельности, сердцевиной которой считается доказывание. Квалификация деяния отражает познанные по делу обстоятельства, а потому она подвержена изменениям, обусловленным установлением новых обстоятельств дела либо иной интерпретацией уже имеющихся в деле доказательств. В ряде случаев необходимость пересмотра первоначально имеющейся юридической оценки деяния может быть вызвана различным подходом к квалификации деяния органами предварительного расследования и лицами, осуществляющими контрольно-надзорные полномочия. Это усугубляется коллизиями и частыми изменениями уголовного законодательства, а также неоправданной, чрезмерной градацией уголовной ответственности на законодательном уровне. В связи с чем при производстве по делу изменение юридической оценки содеянного является достаточно частым явлением ${ }^{6}$. В досудебных стадиях оно оформляется постановлениями о переквалификации общественно опасного деяния, новыми постановлениями о привлечении в качестве обвиняемого и т.п.

Следует учитывать, что многие бланкетные нормы УПК РФ, предписывающего или дозволительного характера, содержат отсылку к статьям Особенной части Уголовного кодекса РФ (напр., ч. 1.1 ст. 108, ст. 151 УПК РФ), либо указывают на определенную категорию преступлений (напр., ч. 1 ст. 108, ч. 1 ст. 186 УПК РФ и др.). Посредством этого устанавливаются пределы полномочий должностных лиц, вводятся гарантии реализации прав участников процесса. Упоминание квалификации содеянного (размера санкции статьи Уголовного кодекса РФ) в нормах УПК РФ регламентирует вопросы обеспечения права граждан на квалифицированную юридическую помощь (п. 5 ч. 1 ст. 51 УПК РФ), «на своего судью» (ст.ст. 30-35 УПК РФ), определяет пределы диспозитивных начал в уголовном судопроизводстве (ст.ст. 20, $23,25,28,28^{1}, 314$ УПК РФ и др.).

Отдавая существенное значение юридической оценке деяния уже в досудебном производстве, законодатель «забывает» о предвари-

\footnotetext{
6 Предварительное исследование показало, что в $25 \%$ изученных производств первоначальная оценка содеянного, изложенная в постановлении о возбуждении уголовного дела, не совпадает с квалификацией преступления, содержащейся в обвинительном заключении (акте), и почти в 45 \% случаев - с юридической оценкой деяния в приговоре суда.
} 
тельном характере досудебного производства, о его подчиненности судебному разбирательству, а, следовательно, и о том, что на первоначальных этапах процесса квалификация общественно опасного деяния всегда является гипотетической, предварительной. На наш взгляд, следует в большей степени учитывать, что познание обстоятельств происшедшего не ограничивается досудебным производством, доказывание продолжается в рамках судебных (главных) стадий. Точность юридической оценки содеянного необходимо требовать лишь применительно к приговору или иному судебному решению, постановленному после проведения судебного следствия, в рамках которого вполне возможно изменение системы доказательств.

Полагаем, что законодательное требование точной юридической оценки содеянного в актах досудебных стадий процесса в ряде случаев является избыточным. Чрезмерная дифференциация процесса по предметному признаку, зависимость порядка производства от тяжести предполагаемого преступления, приводит к ситуации, когда установление обстоятельств, подлежащих доказыванию по делу, почти полностью переносится на начальную стадию уголовного процесса. Это свидетельствует о разбалансировке уголовного судопроизводства, в практике и в законе постоянно расширяются средства и сроки предварительной проверки. В настоящее время процессуальный акт, в котором дается первоначальная юридическая оценка содеянного, во многом предопределяет всю дальнейшую процессуальную деятельность. Зачастую расследование сводится к выполнению формальных процедур по констатированному в постановлении о возбуждении уголовного дела событию происшедшего, оцененному как преступление по определенной статье УК РФ, и подтвержденному значительной доказательственной базой.

В связи с исследованием данного вопроса уместно обратиться к используемому в Уставе уголовного судопроизводства 1864 г. (далее УУС) подходу применения норм материального уголовного закона. В ст. 1 УУС закреплялось: «Никто не может подлежать судебному преследованию за преступление или проступок, не быв привлечен к уголовной ответственности в порядке, определенном правилами Устава». Таким образом, в общих положениях УУС подчеркивалась неразрывная связь материального и процессуального уголовного законодательства. Однако прямого или косвенного требования о необходимости точной юридической оценки содеянного в досудебном производстве уУС не содержал.
При производстве дознания - деятельности полицейской (несудебной) - вынесение какихлибо актов, связанных с юридической квалификацией, не предусматривалось.

Согласно ст. 262 УУС следователь получал право приступить к следствию при наличии двух условий: законного повода и достаточного основания. Определение достаточного основания в законе отсутствовало. В юридической литературе под ним чаще всего подразумевали признаки состава преступления. Так, П.В. Малиновский писал: «Следствие начатое при отсутствии признаков преступления или проступка, подведомственного судебному следователю, и будет начатием следствия без достаточного к тому основания»?. Предварительное следствие могло начинаться, когда обвиняемый был неизвестен, то есть могло вестись исключительно по факту совершения преступления. Необходимость вынесения процессуального решения, отражающего событие преступления и связывающего судебного следователя пределами производства in rem законодательно не предусматривалось. УУС не содержал и прямого указания на акт, посредством которого лицо привлекалось в качестве обвиняемого, ограничиваясь лишь установлением «призыва или привода обвиняемого к следствию» (ст.ст. 377-397 УУС). Таким образом, необходимо согласиться с Е.И. Жидковой, что в ходе предварительного следствия по УУС судебный следователь оставался свободным как в определении круга подлежащих привлечению к ответственности лиц, так и в выборе правовой квалификации деяния, служившего предметом производства ${ }^{8}$.

По окончании предварительного следствия все производство отсылалось к прокурору или его товарищу. Прокурор предавал обвиняемого суду, излагая свое заключение в форме обвинительного акта. В соответствии со ст. 520 УУС в нем должны были быть обозначены: событие, заключающие в себе признаки преступного деяния; время и место деяния, насколько это известно; звание, имя, отчество и фамилия или прозвище обвиняемого; сущность доказательств и улик, собранных по делу против обвиняемого; определение по закону: какому именно преступлению соответствуют признаки рассматриваемого деяния. При этом Сенат разъяснял, что в обвинительном акте следовало указывать только род преступления, а не вид его и степень; вся квалификация дея-

\footnotetext{
Макалинский П.В. Практическое руководство для судебных следователей. Изд. 6-е. СПб., 1907. С. 63.

8 Жидкова Е.И. Формирование пределов производства по делу в досудебных стадиях уголовного процесса: монография. М., 2014. С. 88.
} 
ния могла ограничиваться лишь указанием на какую-либо статью закона9. Таким образом, точная юридическая оценка содеянного в процессуальных документах досудебного производства (включая окончательный акт предварительного следствия) не требовалась.

Конечно, в наше время вряд ли будет уместно и даже практически невыполнимо применять подход УУС относительно юридической оценки содеянного в досудебном производстве. Следует, в частности, учитывать, что составной частью уголовно-процессуального законодательства России являются общепризнанные принципы и нормы международного права. Так, частью 3 ст. 6 Конвенции о защите прав человека и основных свобод закрепляется право обвиняемого в совершении уголовного преступления быть незамедлительно и подробно уведомленным о характере и основании предъявленного ему обвинения. Следовательно, юридическая оценка деяния должна в обязательном порядке содержаться в актах изобличительной деятельности уже на досудебном этапе производства по делу. Вместе с тем возникают вопросы о: 1) целесообразности присутствия в процессе нескольких однородных актов, обозначающих поэтапную деятельность по уголовному преследованию; 2) необходимости точной уголовно-правовой оценки содеянного в решениях предварительного обвинения; 3) целесообразности детальной квалификации деяния в тех процессуальных актах, которые, по сути, носят полицейский (а не судебный) характер (например в постановлении о возбуждении уголовного дела).

Существенным противоречием, заложенным в современном процессуальном законе, является положение, при котором юридическая оценка содеянного, сделанная на предварительном расследовании, выступает в качестве одного из пределов судебного разбирательства. В соответствии со ст. 252 УПК РФ разбирательство проводится только в отношении обвиняемого и лишь по предъявленному ему обвинению. Изменение обвинения допускается только, если этим не ухудшается положение подсудимого и не нарушается его право на защиту.

Е.И. Жидкова резонно замечает, что обвинение, неотъемлемым элементом которого является уголовно-правовая оценка содеянного, является самостоятельным институтом,

\footnotetext{
Щегловитов С. Г. Судебные уставы императора Александра II с законодательными мотивами и разъяснениями. Устав уголовного судопроизводства. Издание третье, исправленное, дополненное и переработанное. СПб., 1887. С. 441-442.
}

и не должна определять содержание института пределов судебного разбирательства ${ }^{10}$. По мнению Л.В. Головко, суд должен быть связан только предъявленными обвинением фактами, но не их юридической оценкой (в т.ч. в худшую для защиты сторону) ${ }^{11}$. В классическом континентальном уголовном процессе (Франция, Германия) суд жестко не связан пределами судебного разбирательства, и при определенных условиях может выйти с точки зрения квалификации за пределы предъявленного обвинения ${ }^{12}$.

Вновь обратимся к УУС. В соответствии со ст. 751 закона на разрешение перед присяжными (или на собственное обсуждение) суд ставил вопросы не только на основании выводов обвинительного акта, но также развивающих, дополняющих или изменяющих их выводов судебного следствия и заключительных прений.

Согласно неоднократным разъяснениям Сената, указания обвинительного акта на признаки и свойства преступления не были обязательными для судьи, решающего дело по существу. В случаях, когда обвинительная власть поддерживала обвинение в пределах обвинительного акта, суд сохранял за собой право поставить сверх главного и дополнительные вопросы, если находил, что судебным следствием обнаружены данные, которые изменяют в чем-то выводы обвинительного акта ${ }^{13}$.

Приведем еще несколько, на наш взгляд, важных разъяснений Сената о положениях УУС, касающихся установления пределов судебного разбирательства и иллюстрирующих возможности усмотрения судьи в вопросе о юридической оценке деяния:

- если фактические признаки преступления в обвинительном акте изложены правильно, но статьи закона приведены ошибочно и им не соответствуют, то суд вправе поставить вопрос о таком обвинении, которое подходит под изложение в окончательном выводе того же акта фактических данных, хотя бы судебного следствия вовсе не производилось или оно представляло только то, что заключало в себе основанный на предварительном следствии обвинительный акт;

10 Жидкова Е.И. Указ. соч. С. 10.

11 Головко Л.В. Казахстан: десоветизация уголовного процесса. Статья 3. В стиле новых тенденций // Уголовное судопроизводство. 2012. № 2. С. 19-20.

12 Головко Л.В. Истоки и перспективы института дополнительного расследования уголовных дел на постсоветском пространстве // Государство и право. 2009. № 11. С. 65-66.

13 Щегловитов С. Г. Указ. соч. С. 665. 
- $\quad$ неправильное указание уголовного закона, под действие которого подводится приписываемое обвиняемому преступление в обвинительном акте или в определении о предании суду, не обязывает окружной суд подчиняться этому определению и применять ту статью закона, которая, вследствие неправильной квалификации преступления, указана в обвинительном акте или определении о предании суду;

- содержащиеся в обвинительном акте указания на статьи закона для суда не являются обязательными;

- если в обвинительном акте сделано указание на какую-либо статью Уложения о наказании без обозначения ее отделов, то суд имеет право поставить в вопросы те определяющие виновность обстоятельства, которые соответствуют одному из пунктов этой статьи;

- разрешение в каждом случае вопроса о том, изменилось ли на суде свойство обвинения, по которому обвиняемый предан суду, и есть ли основание к предложению вопроса о виновности не в том виде, как она означена в обвинительном акте или к постановке сверх вопросов, соответствующих обвинительному акту, других вопросов, вытекающих из судебного следствия и прений сторон, принадлежит суду, рассматривающему дело по существу, и не подлежит контролю со стороны кассационного суда. Единственным ограничением усмотрения суда в постановке дополнительных вопросов по требованию сторон состоит в условии, что такой вопрос может быть постановлен только по доводу, который вытекает из судебного следствия и заключительных прений ${ }^{14}$.

Таким образом, в нормах УУС и разъяснениях Сената обращалось внимание, что суд при разрешении дела имел право самостоятельно и независимо от мнения стороны обвинения применять материальный уголовный закон, в том числе о более тяжком преступлении. Квалификация преступления не выступала в качестве предела судебного разбирательства, неправильная юридическая оценка содеянного не являлась препятствием для рассмотрения дела и могла быть исправлена непосредственно в судебном заседании.

Обращаем внимание, что в современном отечественном процессе вопрос о возможности ухудшить положение подсудимого в судебном разбирательстве становился предметом рассмотрения Конституционного Суда РФ. В своем постановлении от 2 июля 2013 г. № 16-П

14 Там же. С. 667-669.
«По делу о проверке конституционности положений ч. 1 ст. 237 УПК РФ в связи, жалобой гражданина Республики Узбекистан Б.Т. Гадаева и запросом Курганского областного суда» Орган конституционного контроля подтвердил право суда самостоятельно и независимо выбирать подлежащие применению нормы уголовного закона в случаях, когда суд приходит к выводу, что фактические обстоятельства, изложенные в обвинительном заключении, акте или постановлении, свидетельствуют о наличии в действиях обвиняемого признаков более тяжкого преступления либо когда в ходе судебного разбирательства им установлены фактические обстоятельства, являющиеся основанием для квалификации деяния как более тяжкого преступления. Указанным постановлением несоответствующими Конституции РФ были признаны положения ч. 1 ст. 237 УПК РФ, однако в той мере, в какой они в системе действующего правового регулирования, в том числе во взаимосвязи с ч. $2 \mathrm{~cm} .252$ УПК РФ, исключающей возможность изменения обвинения в сторону, ухудшаюшую положение подсудимого, препятствуют самостоятельному и независимому выбору судом подлежащих применению норм уголовного закона. Положения ст. 252 УПК РФ, регламентирующей пределы судебного разбирательства, в указанном выше деле не оспаривались, а потому не были признаны неконституционными. Но, полагаем, что Высший Суд сформулировал ясный посыл законодателю о том, что новый, соответствующий Конституции РФ, уголовно-процессуальный механизм принятия судьей справедливого решения, основанного на правильном применении уголовного закона, может быть достигнут посредством корректировки нормы, регламентирующей пределы судебного разбирательства. К сожалению, имеющаяся в постановлении 16-П установка не была воспринята органами, обладающими законодательной инициативой, и выбрано направление корректировки ч. 1 ст. 237 УПК РФ, предусматривающей возвращение уголовного дела прокурору ${ }^{15}$. Полагаем, что избранный путь является не эффективным, содержит значительные коллизии с принципами и иными нормами УПК РФ (на что мы обращали внимание и ранее ${ }^{16}$ ).

\footnotetext{
Проект Федерального закона о внесении изменений в часть 1 статьи 237 Уголовно-процессуального кодекca Российской Федерации // http://regulation.gov.ru/ project/6357.

16 Муравьев К.В. Возвращение дела прокурору для усиления обвинения или изменение пределов судебного разбирательства в сторону ухудшения: законность и целесообразность // Совершенствование деятельности правоохранительных органов по борьбе с преступно-
} 
Полностью разделяем позицию Е.И.Жидковой, которая отмечает, что законодатель не принимает во внимание, что уголовно-правовая оценка деяния является обязательным элементом института обвинения, но не института пределов производства. Ухудшение положения подсудимого путем простой переквалификации деяния на более тяжкое не связано с изменением производства по кругу фактов (in rem) и по кругу лиц (in personam). В случае же если изменение обвинения сопряжено с изменением предмета производства (например, установление новых фактов совершения преступных деяний и лиц, к ним причастных), то это всегда требует принятия дополнительных процессуальных решений, корректирующих предмет производства по делу (например, возбуждение уголовного дела по новому факту преступного деяния и последующее соединение уголовных дел при наличии предусмотренных к тому оснований, выделение уголовного дела в отношении нового лица для производства предварительного расследования и т.п.) ${ }^{17}$.

Еще раз обратимся к ст. 6 Европейской конвенции о защите прав человека и основных свобод, согласно которой право обвиняемого на справедливое разбирательство дела в разумный срок независимым и беспристрастным судом включает в себя незамедлительное и подробное уведомление о характере и основании предъявленного ему обвинения, а также предоставление достаточного времени и возможности для подготовки своей защиты. Полагаем, что в случаях, когда независимая и беспристрастная правовая оценка деяния судебным органом отличается в сторону ухудшения от квалификации, указанной в акте обвинения, суду необходимо довести обновленную оценку содеянного до подсудимого и обеспечить ему время и возможности для подготовки защиты. Защита будет по-прежнему осуществляться от обвинения, основанного на фактах органов преследования, но в новой уголовноправовой интерпретации, данной судом.

Соответствующий нормам международного права и постановлению Конституционного Суда РФ механизм исправления ошибок (нарушений) применения уголовного закона может предусматривать следующее: в случаях, когда суд приходит к выводу, что имеющиеся в деле доказательства свидетельствуют о необхо-

стью в современных условиях: материалы Международной научно-практической конференции (1-2 ноября 2013 г.) Выпуск 10. Ч. 2 . Тюмень, 2013. С. 184-189 Муравьев К.В. Суд как орган, исправляющий ошибки в применении уголовного закона // Уголовный процесс. 2013. № 11. С. 50-55.

17 Жидкова Е.И. Указ. соч. С. 11-12. димости применения закона о более тяжком преступлении, он по окончании прений сторон высказывает свою позицию о том, каким пунктом, частью, статьей УК РФ следует квалифицировать деяние, в котором обвиняется подсудимый, после чего откладывает судебное заседание на срок, достаточный для подготовки к последнему слову. Подсудимому тем самым обеспечиваются права: знать, какую юридическую оценку деянию, которое явилось предметом обвинения, дает судья; подготовиться к последнему слову, где можно сообщить о новых обстоятельствах, имеющих значение для дела, заявить о необходимости исследования дополнительных доказательств и т.п.

Отметим, что схожий подход о порядке судебной деятельности в случаях необходимости усиления обвинения, был установлен и ст. 752 и 753 УУС. Дело возвращалось к предварительному следствию только в ситуациях, когда при судебном следствии выявлялись не указанные в обвинительном акте преступления. Но процедура возвращения уголовного дела к предварительному следствию не распространялась на новые, хотя бы и отягчающие вину обстоятельства, которые не изменяли сущности и свойства преступления, предусмотренного в обвинительном акте. В объяснительной записке к УУС содержалось: «Если судебное следствие усиливает степень уголовной ответственности, предусмотренной в обвинительном акте, то решение дела необходимо отложить, чтобы не лишить возможности обвинителя зрело обдумать и формулировать обвинение, а подсудимого - приготовиться к защите. Было бы крайне неудобно требовать дополнение или изменение обвинительного акта и пересмотра дела по поводу каждого обвинения, не предусмотренного в обвинительном акте и обнаруженного лишь судебным следствием. Такое обвинение должно подлежать безотлагательному разрешению, если оно относится к действию, которым сопровождалось выведенное в обвинительном акте преступление» ${ }^{18}$.

Согласно разъяснениям Сената, законодателю трудно было постановить подробные и точные правила о том, когда изменившееся на судебном следствии обвинение может быть разрешаемо без нового обвинительного акта. Законодатель указал только руководящее на-

\footnotetext{
8 Устав уголовного судопроизводства с позднейшими узаконениями, законодательными мотивами, разъяснениями Правительствующего Сената и циркулярами министра юстиции. Составлен Членом Харьковской Судебной Палаты М.П. Шрамченко и Юрисконсультом министерства юстиции В.П. Ширковым. Издание четвертое пересмотренное и дополненное. СПб., 1909. C. 700-705.
} 
чало, предоставив суду в каждом случае значительного его изменения обсудить, возможно ли, стесняя средства обвинения и защиты, постановить решение без проведения дополнительного следствия и изменения обвинительного акта. В случае утвердительного решения этого вопроса суд должен был сделать постановление о возможности продолжить рассмотрение дела по обвинительному акту, а председательствующему надлежало предупредить подсудимого, что обнаруженные на суде новые обстоятельства могут повлечь за собою увеличение уголовной ответственности и в случаях просьбы подсудимого приостановить заседание для предоставления ему возможности приготовиться к защите. О соблюдении этого председателем должно было быть удостоверено в протоколе судебного заседания, нарушение же этого обряда составляло повод для отмены приговора, особенно если обвинение усилилось настолько, что перешло от исправительного к уголовному наказанию. Приостановление заседания для подготовки подсудимого к защите могло ограничиваться несколькими часами ${ }^{19}$.

Имелись и другие решения Сената относительно законности действий суда в случаях усиления обвинения против подсудимого. В одном случае достаточным для оставления в силе судебного решения признавалось отсутствие каких-либо заявлений со стороны защитника об отсрочке заседания, если при этом председатель суда обратил внимание сторон на усиливающее вину обстоятельство еще до приступления к заключительным прениям. В другом решении было признано достаточным заявление товарища прокурора после допроса потерпевшего от преступления, что он будет поддерживать более тяжкое обвинение, и отсутствие каких-либо заявлений или защитника о возвращении уголовного дела в палату или о приостановлении заседания ${ }^{20}$.

Таким образом, анализ ст. 751-753 уУС, а также обращение к разъяснениям Сената позволяет сделать вывод, что пределы судебного разбирательства определялись событием преступления (in rem) и обвиняемым (in personam). В отличие от действующего законодательства суд не был связан квалификацией преступления. Он мог исправить неправильную уголовно-правовую оценку деяния, содержащуюся в обвинительном акте, выйти за пределы обвинения (в плане юридической оценки), если в судебном следствии устанавливались обстоятельства, свидетельствующие о необходимости применения материального

\footnotetext{
19 Щегловитов С. Г. Указ. соч. С. 671.

20 Щегловитов С. Г. Указ. соч. С. 672.
}

уголовного закона, предусматривающего более тяжкое преступление.

Полагаем, что исторический опыт формирования пределов судебного разбирательства может быть применен и при совершенствовании современного уголовно-процессуального законодательства России. Напомним, что принятие УУС явилось значимым явлением отечественного судопроизводства. На смену дореформенному инквизиционному розыскному уголовному процессу пришел процесс состязательный, основанный на свободной оценке судом доказательств, рассмотренных в ходе гласного судебного разбирательства ${ }^{21}$. Вряд ли кто из ученых-процессуалистов возьмется утверждать, что предусмотренные УУС процедуры (возможность судом выхода в судебном разбирательстве в плане квалификации за пределы, установленные в обвинительном акте; а в случаях установления новых фактов - направление дела на дополнительное следствие и составление нового обвинительного акта), являются свидетельством инквизиционного процесса. Так почему же в современном процессе мы должны их считать антисостязательными?

Обратим внимание на слова В.Д. Спасовича из прочитанной им незадолго до появления УУС (27 сентября 1860 г.) лекции: «Если мы в самом деле желаем стать на твердую почву закона и не зависеть в наших житейских отношениях от случая, от произвола, то мы должны стараться осмыслять закон положительный, подложить под этот закон логические основания, провести сквозь него разумные начала. Притом нам незачем и отстаивать непогрешимость и безошибочность нашего кодекса. Едва ли могли бы мы в настоящее время разложить это законодательство на составные его элементы, сказать точным образом, что в нем родимое, коренное, и что наносное, что в нем московское и что иностранное, что в нем неизменное и существенное и что переходное и случайное. Оно своеобразно в отрицательном только смысле, по отсутствию в нем определенности» ${ }^{22}$.

Полагаем, что слова В.Д. Спасовича являются актуальными и в настоящее время. При определении концепции нового УПК РФ, призывы о работе над которым содержатся в литературе, при разработке более эффективных норм материального и процессуального уголовного законодательства следует учитывать опыт развития отечественного права.

\footnotetext{
21 Российское законодательство X-XX веков. В девяти томах. Том 8. Судебная реформа. М., 1991. С. 118.

22 Спасович В.Д. О теории судебно-уголовных доказательств в связи с судоустройством и судопроизводством. М., 2001. С. 4.
} 


\section{Библиография}

1. Баршев Я.И. Основания уголовного судопроизводства с применением к российскому уголовному судопроизводству. - М., 2001.

2. Васильева Е.Г.Уголовный процесс: догматико-аксиологическое исследование: монография. М., 2013.

3. Викторский С. И. Русский уголовный процесс. - М., 1911.

4. Головко Л.В. Казахстан: десоветизация уголовного процесса. Статья 3. В стиле новых тенденций // Уголовное судопроизводство. - 2012. - № 2.

5. Головко Л.В. Истоки и перспективы института дополнительного расследования уголовных дел на постсоветском пространстве // Государство и право. - 2009. - № 11.

6. Гуляев А. П. Цели, задачи и принципы как фундаментальные положения уголовно-процессуального права: по закону, теории и практике // Рос. следователь. - 2012. - № 16.

7. Жидкова Е.И. Формирование пределов производства по делу в досудебных стадиях уголовного процесса: монография. - М., 2014.

8. Макалинский П.В. Практическое руководство для судебных следователей. Изд. 6-е. - СПб., 1907.

9. Муравьев К.В. Возвращение дела прокурору для усиления обвинения или изменение пределов судебного разбирательства в сторону ухудшения: законность и целесообразность // Совершенствование деятельности правоохранительных органов по борьбе с преступностью в современных условиях: материалы Международной научно-практической конференции (1-2 ноября 2013 г.). - Тюмень, 2013.

10. Муравьев К.В. Суд как орган, исправляющий ошибки в применении уголовного закона // Уголовный процесс. - 2013. - № 11.

11. Прошляков А.Д. Взаимосвязь материального и процессуального уголовного права. - Екатеринбург, 1997.

12. Спасович В.Д. О теории судебно-уголовных доказательств в связи с судоустройством и судопроизводством. - М., 2001.

13. Фойницкий И.Я. Курс уголовного судопроизводства. Т. 1. - СПб., 1996.

14. Щегловитов С. Г. Судебные уставы императора Александра II с законодательными мотивами и разъяснениями. Устав уголовного судопроизводства. Издание третье, исправленное, дополненное и переработанное. - СПб., 1887.

\section{References}

1. Barshev Ya.I. Osnovaniya ugolovnogo sudoproizvodstva s primeneniem k rossiiskomu ugolovnomu sudoproizvodstvu. - M., 2001.

2. Vasil'eva E.G. Ugolovnyi protsess: dogmatiko-aksiologicheskoe issledovanie: monografiya. M., 2013.

3. Viktorskii S.I. Russkii ugolovnyi protsess. - M., 1911.

4. Golovko L.V. Kazakhstan: desovetizatsiya ugolovnogo protsessa. Stat'ya 3. V stile novykh tendentsii // Ugolovnoe sudoproizvodstvo. - 2012. - № 2.

5. Golovko L.V. Istoki i perspektivy instituta dopolnitel'nogo rassledovaniya ugolovnykh del na postsovetskom prostranstve // Gosudarstvo i pravo. - 2009. - № 11.

6. Gulyaev A. P. Tseli, zadachi i printsipy kak fundamental'nye polozheniya ugolovno-protsessual'nogo prava: po zakonu, teorii i praktike // Ros. sledovatel'. - 2012. - № 16.

7. Zhidkova E.I. Formirovanie predelov proizvodstva po delu v dosudebnykh stadiyakh ugolovnogo protsessa: monografiya. - M., 2014.

8. Makalinskii P.V. Prakticheskoe rukovodstvo dlya sudebnykh sledovatelei. Izd. 6-e. - SPb., 1907.

9. Murav'ev K.V. Vozvrashchenie dela prokuroru dlya usileniya obvineniya ili izmenenie predelov sudebnogo razbiratel'stva $\mathrm{v}$ storonu ukhudsheniya: zakonnost' i tselesoobraznost' // Sovershenstvovanie deyatel'nosti pravookhranitel'nykh organov po bor'be s prestupnost'yu $\mathrm{v}$ sovremennykh usloviyakh: materialy Mezhdunarodnoi nauchno-prakticheskoi konferentsii (1-2 noyabrya 2013 g.). - Tyumen', 2013.

10. Murav'ev K.V. Sud kak organ, ispravlyayushchii oshibki v primenenii ugolovnogo zakona // Ugolovnyi protsess. - 2013. - № 11 .

11. Proshlyakov A.D. Vzaimosvyaz' material'nogo i protsessual'nogo ugolovnogo prava. - Ekaterinburg, 1997.

12. Spasovich V.D. O teorii sudebno-ugolovnykh dokazatel'stv $\mathrm{v}$ svyazi s sudoustroistvom i sudoproizvodstvom. - M., 2001.

13. Foinitskii I.Ya. Kurs ugolovnogo sudoproizvodstva. T. 1. - SPb., 1996.

14. Shcheglovitov S.G. Sudebnye ustavy imperatora Alexandra II s zakonodatel'nymi motivami i raz"yasneniyami. Ustav ugolovnogo sudoproizvodstva. Izdanie tret'e, ispravlennoe, dopolnennoe i pererabotannoe. - SPb., 1887. 